\title{
Habits in Consumption, Transactions Learning And Economic Growth.
}

\section{Constantin T. Gurdgiev}

\author{
Department of Economics \\ and \\ Policy Institute \\ Trinity College, Dublin \\ The Open Republic Institute, Dublin
}

gurdgic@tcd.ie

April 2005.

\begin{abstract}
.
This paper presents a model of endogenous growth in the presence of habit formation in consumption. We argue that in addition to the traditional disutility effects of habitual consumption, the past history of consumption represents a past record of transactions as well. As a result, the knowledge acquired in the process of past consumption leads to efficiency gains in allocating time to other activities. In particular, the investment technology in broad household capital can be seen as benefiting from the habitual consumption knowledge, while being subject to the costly new consumption pathways learning. These learning-by-consuming effects imply a faster speed of convergence to the steady state growth rate in consumption and a higher steady state ratio of capital to habits. Alternatively our model allows for the case where new consumption is associated with the accumulation of broad capital, as is consistent with the case where consumption goods can also be used in production. In this case convergence to steady state growth rate is slower.
\end{abstract}

JEL Classification: D13, E21, E22, O40

Key Words: habits, endogenous growth, transactions cost, capital. 


\section{Introduction.}

Abramovitz (1956) and Solow (1956) found that most of the observed economic growth cannot be explained by conventional labour and capital measures. In addressing the issue, both authors stressed that the changing quality of labour may play an important role in accounting for historical growth.

\subsection{The state of traditional thinking.}

One way to think about the changes in efficiency of labour improvements is to introduce the concept of learning by doing. Arrow (1962) cites the empirical regularity that after a new aircraft design is introduced, the time required to build the frame of the marginal aircraft is inversely proportional to the number of the same model of the aircraft produced. Thus, the accumulation of knowledge occurs not as a result of deliberate efforts but as a side effect of conventional economic activity. The efficiency improvements in such a case depend on how much knowledge is generated by spillovers.

The notion of investment in human capital, pioneered by T. Schultz (1973), represents a different approach to modelling improvements in efficiency. Denison $(1967,1985)$ emphasises that skills and knowledge can be acquired by education and on-the-job training. Later models of economic growth, such as Lucas (1988), Romer (1986) and Mankiw, Romer, Weil (1992) place more emphasis on the investment in human capital as an important factor contributing to growth. Hamilton and Monteagudo (1997) try to explain changes in the growth rate over time. They find that investment in human capital cannot account for changes in growth rates over time. However, Benhabib and Spiegel (2002) find that post-educational skills attainment effects on current growth rates become significant if education facilitates the adoption of new technologies, which are continuously invented at 
an exogenous rate. Therefore, productivity growth and the rate of innovation should increase with the level of educational attainment.

Thus, there are two broadly defined schools of thought concerning the nature of learning. Most of the literature above treats educational technology as exogenous. Household activities, such as consumption, savings and leisure, that require time and may compete for resources with investment in education do not effect the capital stock and investment in capital acquisition by the households outside their effect on the budget and time constraints.

A somewhat different view is provided by Lucas' and Romer's approach, which claims that persistent growth is generated endogenously from the actions of individuals conducting their everyday activities in the economy. These actions are fully integral with respect to other decisions made by the households. The implication of this reasoning is that countries do not need to converge in income per capita, even if they have the same preferences and technology. Nevertheless, there are two distinctive points to emphasise. Lucas' model supports the relationship between productivity growth and the rate of human capital accumulation, whereas Romer argues that the level-effect of education is important.

\subsection{An alternative view.}

Despite the significant successes in the development of the economic models that endogenise the primary sources for growth, several problems remain unresolved. First, all the models mentioned above imply one-directional causality from higher savings to higher growth. As argued by Carroll, Overland and Weil $(1997,2000)$, hereinafter referred to as COW, there exists growing empirical evidence to suspect that this theoretically predicted causality is reversed in the real world.

Second, implicit in the model of human capital accumulation, the trade-off between time spent learning as opposed to consuming occurs solely along the lines of foregoing labour 
input and/or consumption in favour of greater investment in learning. Yet, investments of time into learning impose additional tradeoffs that can be associated with transactions time required to support consumption. Becker (1965) recognises this:

There is no exception in the traditional approach to the rule that a pure rise in earnings would not induce a decrease in hours worked ${ }^{l}$.... if the time and earnings... were negatively correlated, a pure rise in earnings would induce substitution toward timeintensive commodities, and thus away from work.

In this context, in the presence of a habitual consumption, it is natural to differentiate between historical consumption and new consumption not only in terms of marginal utility, but also in terms of time costs associated with each type of consumption.

Suppose that habitual consumption is linked to the established search and transactions pathways captured by the representative agents' past history. In contrast, new consumption requires development of pathways, implying the presence of time costs of new transactions. These costs may act to reduce resources available for human capital investments. Shopping in a familiar grocery store for the habitual consumption basket of goods may be less costly in terms of time, than shopping in a new environment. Lucas acknowledged that learning the new spending pathways in response to a windfall increase in income (in his case, the proceeds of the Nobel Prize) can be a costly enterprise vis-à-vis alternative uses of time. In addition, considering the linkage between productive technologies (e.g. computers and the internet), some of the habitual consumption may generate a positive productivity spillover (e.g. people familiar with e-retailing also tend to have higher productivity in IT systems).

Alternatively, we can consider the possibility that some consumption goods generate both utility from consumption and the skills augmentation that enhances human capital of the

\footnotetext{
${ }^{1}$ In the context of this paper - in resources allocated to broad capital accumulation.
} 
households. Such goods are manifold in today's economy: computers, personal organisers, electronic games, mobile phone services, and even some entertainment goods, such as interactive programming and multimedia news delivery services. In this scenario, the habitual component of consumption does not provide enhancements of capital stock, while addition of a new consumption good may produce strong learning possibilities.

Today, economists recognise the importance of consumption link to alternative uses of time. Becker (1965) pioneered a model of labour/leisure trade-off that involves direct reference to time intensity of consumption. His model of labour supply implies that households will have preferences over consumption of goods that are linked to the time costs of such consumption, not just to the price of these goods. As a result of this, the households' responses to changes in income and wages are magnified by the possibility of switching into and out of consuming time-intensive goods. Recently, this aspect of human behaviour received significant attention in business literature (e.g. McKinsey Quarterly, August 2003).

Hamilton and Monteagudo (1998) show that the initial level of output acts as an important determinant of growth. This result can be explained in part by their failure to properly measure the effects of the agents' choices in the goods market on household's capital stock. Income growth may be tied to consumption growth and savings, which relate to the changes in the stock of habits. The latter may have an effect on the rate of growth in broad capital. Thus, differences across countries along the transition path to the steady state, as well as in the steady state itself can be at least partially captured by the habits formation mechanism (as in COW) and by the effects of habits on the households' accumulation of a broadly defined capital (as done in the present paper).

To the best of my knowledge, no macroeconomic model of growth has so far examined a possibility for the existence of the costs and benefits of new and habitual consumption and their implications for the acquisition of capital. 


\subsection{Internal v. External Habits and Learning.}

Hereinafter we develop a model of referenced consumption in the presence of endogenous learning effects. Learning arises in the process of converting the new post-shock household consumption into the stock of general knowledge that augments the stock of broadly defined household capital. In the context of the preceding discussion, we assume that the growth rate in capital can be a decreasing function of the consumption to habits ratio (the case of costly learning of new pathways) or an increasing function of new consumption (in such a case, new post-shock consumption yields immediate benefits in knowledge). We discuss these issues further in section 2.1 below.

We assume that agents are outward-looking. This implies that in their decision-making they use past stock of consumption as their reference level without choosing directly the level of habits stock. We impose this assumption for the following reasons:

1. As shown in $\mathrm{COW}$, for representative agent, incorporation of internal habits does not fundamentally alter the model behaviour.

2. The learning effects of new consumption apply more to the external reference stock of habits than to internal habits (we elaborate on this below).

3. Empirically, evidence on external habits is stronger than that on the internal, especially at the aggregate level.

With respect to the argument made in (18), we can view the effect of habits on learning-bydoing as being driven by two possible forces. The first force is the learning effects of individual household engaging in the process of new consumption relative to habitual consumption. As households increase their consumption, the new consumption may require acquisition of new skills and technologies. When a person purchases a computer game, whatever skills he or she acquires may be driven by individual learning alone. 
Alternatively, new consumption may require learning of the new skills that are available outside the household. Learning to play a new game may be equivalent to acquiring knowledge from someone else. In this case, a person will learn not by discovery of the entirely new information, but by acquiring information from someone, who already possesses it. This implies that the reference level of knowledge for the new-consumption household is the habitual stock of consumption possessed by an average household.

We assume that in our context, implicitly, the new creation of knowledge plays only insignificant part in overall household learning. Instead, the lion share of new broadly defined household capital comes from learning the skills available in the economy. Hence, our households do not optimise by directly choosing their reference level of consumption.

With this in mind, the paper proceeds to develop a simple extension of the COW framework to incorporate a link between habits, new consumption and capital accumulation. Part 2 presents the proposed modification of the capital accumulation process and derives steady state relationships. Part 3 concludes the paper by revisiting the issue of the linkage between new and habitual consumption and the law of motion for the broader capital stock.

\section{Theoretical Model.}

\subsection{Production and Capital.}

This paper presents a model of endogenous growth that incorporates a direct link between consumption $\left(c_{t}\right)$, the stock of habits $\left(h_{t}\right)$, and broad capital $\left(x_{t}\right)$. We treat capital in a composite (broad) sense, as combining both human and physical forms of capital.

Composite capital $\left(x_{t}\right)$ enters the Rebelo-AK type production function:

$$
Q=A x_{t}
$$


and evolves according to the following law of motion:

$$
\dot{x}_{t}=(A-\delta) x_{t}-\frac{c_{t}^{\alpha}}{h_{t}^{\alpha}} c_{t}
$$

so that $x_{t}$ is a function of physical and human capital, and the growth rate in capital is:

$$
\frac{\dot{x}}{x}=A-\delta-\left(\frac{c_{t}}{h_{t}}\right)^{\alpha} \frac{c}{x}=[A-\delta]-f(c, h) \frac{c}{x}
$$

where $f_{c}>,<0$ and $f_{h}<,>0$. Note that in equation (1) above, there are two possibilities:

- $\quad 0<\alpha<1$ and relative consumption $\frac{c}{h}>1$ outside the steady state, in the steady state, $\frac{c}{h}=1$ and habits stock catches up fully with consumption;

- $\alpha<0$.

The first case corresponds to the situation where the growth rate in broad capital is a decreasing function of consumption to habits ratio. This case is the subject of our main discussion. Assume that habitual consumption supports new knowledge. Then habitual level of consumption in the society can act to increase the speed at which the broadly defined capital is acquired. On the other hand, new consumption, before being accumulated into the habits stock, may require learning of the new pathways associated with time and effort costs. Thus new consumption will tend to reduce temporarily the growth rate in the capital stock by transferring time away from accumulating capital stock in the process of catching up of the habits stock. ${ }^{2}$

Our model provides richer interactions between habitual consumption, new consumption and capital. In traditional habit models, such as COW, stronger habits imply a higher growth rate in capital through a higher steady state in consumption. As consumers are more willing 
to postpone consumption over time due to higher disutility effects of habitual consumption, the economy is accumulating capital out of savings. In this sense, savings are Grangercaused by growth. Our effect as shown in equation (1) amplifies these effects. ${ }^{3}$

Our model allows for the possibility of relating the costs of new consumption in terms of capital accumulation, $\alpha$, with the strength of habits $(\gamma)$ and the speed of habits stock adjustment to the steady state $(\lambda)$, defined below.

Finally, from equation (1) and production function specification preceding it, in the absence of technological progress, $\dot{Q}=A \dot{x}$, so that the increase in reference stock of past consumption acts to increase the rate of growth in economy, while an increase in the new consumption acts to lower it. A higher stock of reference stock relative to new consumption implies that social norms of competition in consumption (such as keeping-up with the Joneses') are support faster incorporation of new consumption into the reference norm.

\subsection{Preferences and Optimisation.}

Representative agents with outward-looking habits maximise the life-time utility stream:

$$
\max _{\left(c_{t}\right)} \int_{0}^{\infty} U\left(c_{t}, h_{t}\right) e^{-\theta t} d t \quad \text { subject to } U\left(c_{t}, h_{t}\right)=\left[\frac{c_{t}}{h_{t}^{\gamma}}\right]^{1-\sigma} / 1-\sigma
$$

and the laws of motions for capital:

\footnotetext{
${ }^{2}$ From equation (1), habitual stock of consumption increases the rate of capital accumulation, while the innovations in consumption act to lower the rate of growth whenever $0<\alpha<1$.

${ }^{3}$ In a sense we can interpret the stock of habits as a reference point for both consumption of traditional commodities and consumption of the learning commodities. Thus the model is consistent with the model of human capital accumulation that incorporates the possibility of utility-generating learning. Unlike the utility-generating models of learning, our model has payoffs to investment in the periods following the period of new consumption. Of value is also the nature of the timing of the payoff itself being spread over a long period of time, endogenously determined by the rate of convergence of habits stock to consumption, as given below by the parameter in the law of motion for habits. Via the speed of habits stock adjustment, as discussed below, we in part can endogenise the capital formation mechanism into the structure of the representative agent's preferences.
} 
$\dot{x}_{t}=(A-\delta) x_{t}-\frac{c_{t}^{\alpha+1}}{h_{t}^{\alpha}}=(A-\delta) x_{t}-f\left(c_{t} / h_{t}\right) c_{t}$

With respect to the law of motion for habits, we assume that

$$
\dot{h}_{t}=\lambda\left(c_{t}-h_{t}\right)
$$

Since habits are external, consumers care only about the referential nature of habits without incorporating the determination of habits into their decisions.

In the specification of preferences provided above, parameter $0 \leq \gamma<1$ determines the importance of relative utility, so that the strength of habits in the utility function rises with $\gamma$. In the specification for the habits law of motion (4), parameter $0 \leq \lambda<1$ captures the speed at which the habits converge towards consumption. $\lambda>0$ determines the relative importance of consumption across different periods. The larger $\lambda$ is, the more important consumption in the recent past will be, relative to the distant history of choices.

Deriving the first order equations with respect to $c_{t}$ and $x_{t}$ we have:

$$
\begin{aligned}
& U_{c}=\pi_{t}(\alpha+1) y_{t}^{\alpha} \\
& \dot{\pi}_{t}=\pi_{t}[\theta+\delta-A]=-\tilde{A} \pi_{t}
\end{aligned}
$$

where $\pi_{t}$ is a multiplier on the capital law of motion and $y_{t}=\frac{c_{t}}{h_{t}}$ denotes consumption to habits ratio.

Solving equations (5) and (6), first denote consumption growth rate as $z_{t}=\frac{\dot{c_{t}}}{c_{t}}$, so that $z_{t}=\frac{\tilde{A}+\lambda\left(y_{t}-1\right)[\gamma(\sigma-1)+\alpha]}{\sigma+\alpha}$ 
Appendix 1 supplies details of derivations. As in the set-up above, hereinafter we closely follow the COW methods in order to focus on the effects of the innovation in capital accumulation process proposed above. Setting $\alpha=0$ attains the results shown in COW, while setting $\gamma=0=\alpha$ attains the results for the standard model without habits.

We first solve the case of $0<\alpha<1$, leaving the case of the positive effects of new consumption relative to habits on the human capital growth for later. The detailed discussion of the effects of the habits parameters, $\alpha, \gamma$ and $\lambda$ is postponed until after the discussion of the steady state below.

From equation (7):

$z_{t}=z_{t}^{C O W} \frac{\sigma}{\sigma+\alpha}+\frac{\alpha}{\sigma+\alpha} \lambda\left(y_{t}-1\right)$

$z_{t}>,<z_{t}^{C O W}$ if and only if $y_{t}>,<1+\frac{\tilde{A}}{\lambda(\sigma-\gamma(1-\sigma))}=y_{S S}^{C O W}$. Hence, for an economy

starting at a low ratio of new consumption relative to habits stock, consumption growth in our model exceeds the COW benchmark.

In particular, for the environment of moderate economic growth, as parameterised in COW, $\tilde{A}=A-\delta-\theta=0.03$, corresponding to the COW steady state growth rate of $2 \%$, this requires the ratio of consumption to habits to be closer to 1 . At the same time, a higher ratio of new consumption to habits yields the opposite effect, that can be attributed to the direct effect of habits on capital accumulation. For low values of $y_{t}$, the habits stock is relatively large so that the cost of new consumption in terms of foregone capital is relatively small. As consumption is adjusted upward, the habits stock also rises, causing a positive effect on capital accumulation. Agents are willing to adjust their consumption at a faster pace than in the COW model along the transition path to the steady state. 
By (7), the rate of growth in consumption along the balanced growth path depends, as in traditional habits models, on technological innovation, depreciation, time preferences, the strength of habits in the utility $(\gamma)$ and the speed at which habits catch up with consumption ( $\lambda$ ). The overall effect of $\lambda$ in our model is amplified by the presence of the cost effects of habits. As $\lambda$ rises, habits move faster towards the steady state, so that capital accumulation is less impacted by new consumption. The learning process being faster, the economy will move faster towards the steady state and thus consumption growth along the convergence path will be higher for any given level of consumption relative to habits.

To establish this result formally, from equation (7):

$$
\frac{d z}{d \lambda}=\frac{\left(y_{t}-1\right)[\gamma(\sigma-1)+\alpha]}{\sigma+\alpha}>\left(\frac{d z}{d \lambda}\right)_{C O W}=\frac{\left(y_{t}-1\right) \gamma(\sigma-1)}{\sigma}>0 \text {. }
$$

With respect to the strength of habits in the utility function, parameter $(\gamma)$, as in the case of $\lambda$, the greater is the role of habits in the utility function, the faster the economy will move to the steady state. The higher is $\gamma$, the more representative agent will care about the ratio of consumption to habits and the less she will care about the actual new consumption. As a result, the households will tend to favour a faster transition of new consumption to habits.

However, unlike the traditional habits in consumption models, the growth rate in consumption also depends directly on the importance of the reference stock in the accumulation of the composite capital. As the importance of habits in determining capital stock adjustment costs rises, the growth rate of consumption along the steady state path rises as well. From equation (7), $\frac{d z}{d \alpha}>,<0 \Leftrightarrow y_{t}>,<1+\frac{\tilde{A}}{\lambda[\sigma-\gamma(\sigma-1)]}$, so that the effect of the 'learning', $\alpha$, on the growth rate of consumption along the balanced growth path will depend on the ratio of consumption to habits. A high ratio implies that there is a significant innovation consumption component relative to habits stock. 


\subsection{Analysis of the Steady State.}

To find the steady state growth rate of consumption, differentiate the relative consumption ratio with respect to time and use equations (3), (5) and (7) to derive:

$$
\begin{aligned}
& z_{s s}=z_{s s}^{C O W}=\frac{\tilde{A}}{\sigma-\gamma(\sigma-1)} \\
& y_{S S}=1+\frac{z_{S S}}{\lambda}=y_{S S}^{C O W}
\end{aligned}
$$

Both consumption growth and the ratio of consumption to habits are constant in the steady state. Figure 1 below shows the results.

\section{Figure 4.1. Stable Arm Phase Diagram for Consumption Growth.}

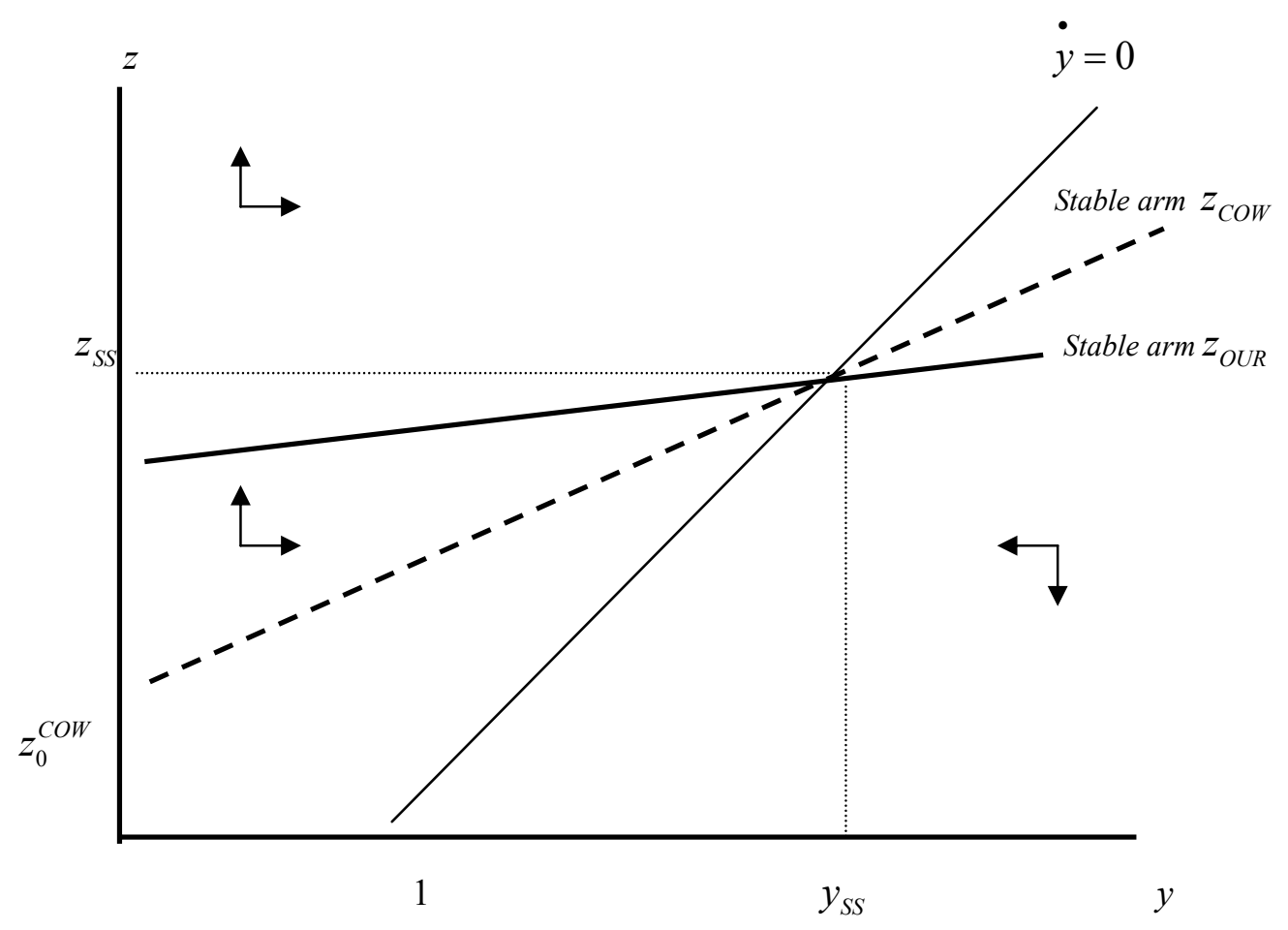

Our steady state solutions are independent of the learning parameter, $\alpha$. As in standard learning-by-doing models, the learning effects of the habits stock relative to consumption in our model accrue along the balanced path. Off the locus of stationarity, if the growth rate of consumption growth exceeds that of the steady state, so that $\dot{z}>0$, then $\dot{y}>0$. Thus above 
the $\dot{y}=\dot{z}=0$ locus, both consumption to habits ratio and the speed of consumption growth are increasing. Intuitively, as consumption growth increases, at first consumption grows faster than habits stock, so that the ratio of consumption to habits is increasing as well. As we get closer to the stable arm, the difference between consumption growth rate and the growth rate in the ratio of consumption to habits is diminished. This result is standard for the habit formation models in consumption: the further away from the steady consumption to habits ratio we are, the more willing are agents to adjust their consumption.

Next, we want to determine the level of the capital stock relative to the habits stock attainable in the steady state. Differentiating $x / h$ with respect to time, using equations (3) and (4) above, and setting $(x / h)=\dot{\eta}=0$ we have:

$\left(\frac{x}{h}\right)_{s s}=\eta_{s s}=\frac{y_{s s}^{\alpha+1}}{\tilde{A}+\theta-\lambda\left(y_{s s}-1\right)}$

Figure 4.2. Phase Diagram in $\left(y, \frac{x}{h}\right)$ space.

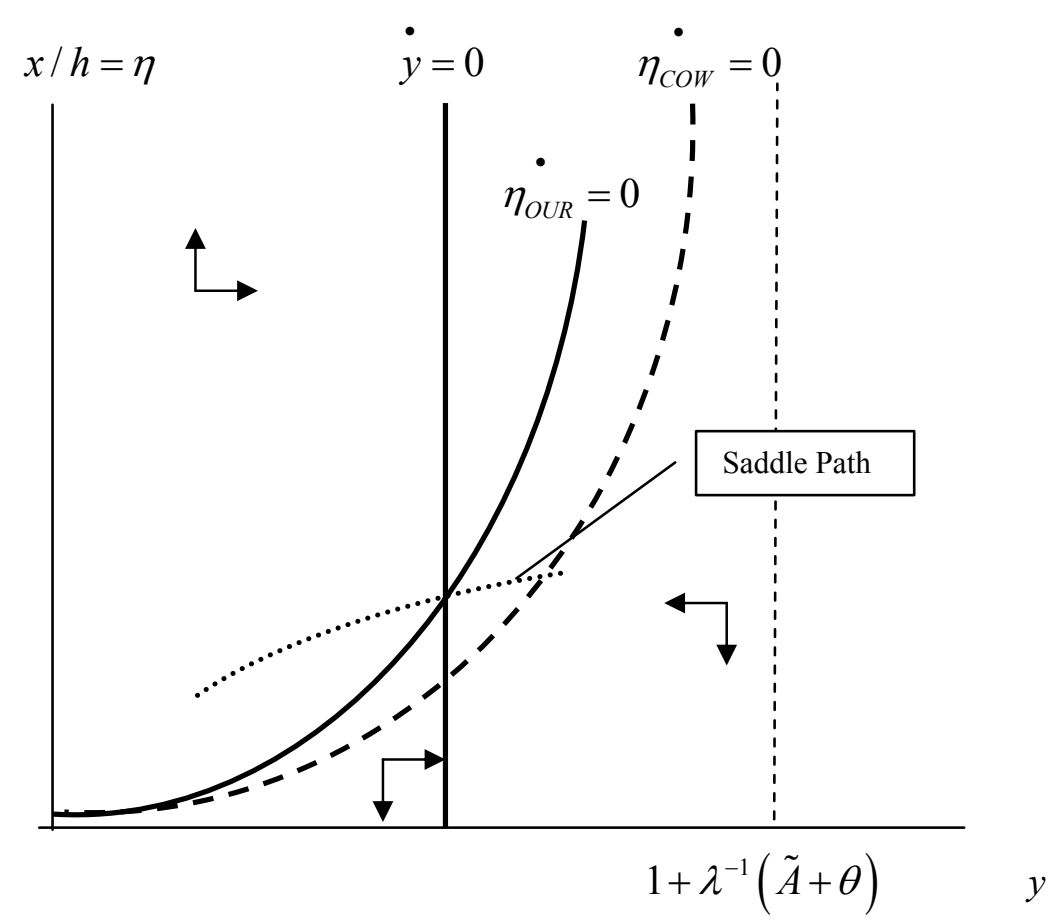


As in the COW case, our steady state stock of capital relative to habits depends on the disutility of habits via the steady state ratio of consumption to habits. However, in addition to this indirect effect, relative (new) consumption also has a predicted direct effect through its link to the capital accumulation process. Comparing the stock of capital relative to habits in our model to that of the benchmark COW model, we can see that under condition (10) our model yields a higher ratio of capital to habits than COW. Furthermore, our steady state ratio of capital to habits is increasing in the strength of habits in the determination of the capital formation $(\alpha)$.

Figure 4.2 above shows the relationship between the ratio of steady stock level of composite capital and the ratio of consumption to habits stock in our model. The vertical line represents the locus of stationarity for the ratio of consumption to habits. This locus is determined by the realisation of the steady state growth rate in consumption. For a higher growth rate in consumption, the locus of stationarity of $y$ will be to the right of the depicted one. The saddle path in Figure 2 above is flatter than the saddle path in COW.

Traditional habit formation effect in the utility function is to increase the CRRA. In the habit case, $\sigma$ estimates would understate the true value of the CRRA parameter. COW discusses this in detail. In our model as shown in equation (18) both the strength of habits in the utility $(\gamma)$ and the strength of habits in the learning mechanism $(\alpha)$ have an effect of increasing the CRRA. Hence, the learning effect and direct habit effect reinforce each other.

Overall, in the presence of habit formation, the response of savings to changes in the growth rate of income is higher than in traditional models. This effect is amplified in our model. Savings become more responsive to changes in income as the learning effect reinforces the traditional habits effect along the balanced growth path. The direct effect of habits is to increase the infinite horizon intertemporal elasticity of substitution. The learning effect 
implies that consumers also face higher costs of increasing consumption immediately. However, at the same time, a faster adjustment of consumption yields faster growth rate in habits, so that the capital accumulation becomes less costly in the future. This translates into a higher steady state ratio of capital stock to habits than in the COW benchmark model and faster adjustment to the new steady state.

Considering the effect that habits play in the utility function, an increase in the importance of habits in the within-period utility function $(\gamma)$ is linked in our model to a higher savings rate relative to $\mathrm{COW}$ (which in turn is also higher than in the traditional real business cycle models). Outside the steady, a lower consumption to capital ratio than in COW (which itself is below the traditional models), as well as a higher growth rate in consumption imply that the model moves to the steady state at the rate faster than in both COW and standard real business cycle and life cycle models.

With respect to the steady state growth rates, holding technological progress parameter $A$ constant, by equation (8) above,

$$
\left(\frac{\dot{c}}{c}\right)_{S S}=\left(\frac{\dot{h}}{h}\right)_{S S}=\left(\frac{\dot{x}}{x}\right)_{S S}=\left(\frac{\dot{Q}}{Q}\right)_{S S}
$$

\section{Case of Learning from New Consumption: $\alpha<0$.}

An interesting variation to the model can be considered by reversing the effect of new consumption relative to habits in the learning mechanism. Assume that $\alpha<0$, so that the addition of new consumption acts to enhance capital accumulation. As mentioned in the Introduction, this scenario corresponds to the case where new consumption involves goods that can generate learning of skills that augment human capital of the household. 
Using the solutions presented in (5) we must restrict $0>\alpha>-1$. In this case, the balanced growth path for consumption given in (7) can be described under the following two cases:

Case 1. For $\gamma(\sigma-1) \leq-\alpha$, the direct habits effect on growth rate of consumption is less than the learning effect of new consumption.

Case 2. For $\gamma(\sigma-1)>-\alpha>0$, the direct habits effect exceeds the learning effect of new consumption on the growth rate along the balanced path.

Since it is possible to assume that $\gamma(\sigma-1)<1$ (as is parameterised in COW at 0.5 ) we shall consider both cases.

In Case 1, a stronger effect of learning implies that the $\dot{z}_{t}=f\left(y_{t}\right)$ locus is negatively sloped. As the consumption to habits ratio increases, growth in capital rises as well. Hence, households will maintain slower adjustment in consumption, and the growth rate in consumption will fall. From equation (7), in this case, $\dot{z}_{t}=0$ locus is either coincident with $\dot{y}_{t}=0$ locus as before, or whenever $\gamma(\sigma-1)=-\alpha$, the locus is horizontal.

Since with $\alpha<0$, in addition to the traditional disutility of habits, the rising habits also exert a cost on capital formation. This implies that households will be more willing to postpone consumption. Thus, starting with a low consumption to habits ratio, households move to the new steady state by lowering the growth rate of consumption. In this case, growth causes savings. Furthermore, our link between consumption to habits ratio and the growth rate in capital reinforces the COW results. These changes imply that in Figure 1, the new locus of stationarity will be down-sloping in case 1 .

In Case 2, a weaker effect of learning relative to the traditional habits effect implies that transition dynamics are slower in this case than in COW. The reason for this result is that 
new consumption generates learning effects on increasing broad household capital. Thus, households are more responsive to the negative effects of habits on the utility than in the traditional model, as the dual costs of habits on utility and capital accumulation apply. This implies that given level of growth results in lower savings in Case 2 than in COW, while it will result in higher savings in Case 1 than in COW.

\section{Conclusions.}

In their model, Barro, et al (1995) postulated that the ability of the standard theories in explaining empirical findings concerning convergence and growth in general must rest on the broader interpretation of the capital to include both physical and human capital in order to justify a high empirical share of capital in production required to derive the desired results. At the same time, literature starting with Solow (1956) have addressed the issues of capital formation in context of learning by doing.

This paper proposes to extend the learning-by-doing mechanism to incorporate new consumption and the habitual stock of past consumption. In the process of time and resource allocation to learning new consumption pathways, households trade over time and across both habitual stock and new consumption, while being fully aware about the relatively costly nature of new consumption in terms of foregone investments.

As a result of this, the model presented above incorporates a direct link between the ratio of new consumption to habitual consumption and the capital accumulation process for a broadly interpreted capital stock. We compare the predictions of the model against the benchmark habits in consumption model of economic growth presented in Carroll, Overland and Weil (2000), denoted throughout as COW. The model finds that accounting for the alternative use of time and other costs in trading across current consumption, habitual consumption and time imply that: 
- Broader capital growth along the balanced path is dependent positively on the learning effects of new consumption relative to habits;

- Capital growth can exceed growth in consumption along the path to the steady state;

- The presence of costs of new consumption relative to habits results in a faster growth in consumption along the balanced growth path, lower ratio of consumption to habits, higher steady growth rate in capital, and higher output growth;

- The steady state consumption growth and consumption to habits ratio are increasing with the strength of habits in the utility, as in the COW model;

- The steady state growth in capital exhibits a stronger response to changes in the strength of habit formation parameters in our case than in COW;

- In our model, growth rates are amplified by the higher rate of capital growth.

Hence, the overall model predictions retain the attractive properties of general habit formation models with respect to delayed responses in consumption and capital to exogenous income shocks, as shown in COW. Our model confirms the causality link between growth and savings established in the COW model, while changing the speed of adjustment to the steady state.

\section{Bibliography.}

Arrow, K. J. "The Economic Implications of Learning by Doing” Review of Economic Studies, 29, June 1962.

Barro, R., Mankiw, N. and Sala-I-Martin, X."Capital Mobility in Neoclassical Models of Growth”. The American Economic Review, Vol.85, Number 1, March 1995.

Becker, G. S. "” Theory of the Allocation of Time” The Economic Journal 75, No.299, pages 493-508.

Benhabib, J. and Spiegel, M. "Human Capital and Technology Diffusion" Federal Reserve Bank of San Francisco, Working Papers in Applied Economic Theory, No.2003-02, 2002. 
Carroll, C., and Weil, D. "Savings and Growth: A Reinterpretation". CarnegieRochester Conference Series on Public Policy, 40, 1994.

Carroll, C., Overland, J. and Weil, D. "Comparison Utility in a Growth Model" Manuscript, 1997.

Denison, E. "Why Growth Rates Differ" Washington DC: The Brookings Institution, 1967.

Denison, E. "Trends in American Economic Growth". Washington DC: The Brookings Institution, 1985

Hamilton, J. D. and Montegaudo, J. “The Augmented Solow Model and the Productivity Slowdown”. UCSD Economics Discussion Paper, 97-28, 1997.

Lucas, R. "On the Mechanics of Economic Development”, Journal of Monetary Economics, 22(1), 1988.

Mankiw, N., Romer, D. and Weil, D. "A Contribution to the Empirics of Economic Growth”, Quarterly Journal of Economics, May 1992, 107(2).

Romer, P. “Increasing Returns and Long Run Growth”, Journal of Political Economy, 98, October 1986.

Solow, R. "A Contribution to the Theory of Economic Growth", Quarterly Journal of Economics, February 1956, 70(1).

\section{Appendix 1. Mathematical Derivations of the Steady State Equations.}

Here we proceed to show the algebra involved in deriving the steady state equations (8)-(1o) presented in the paper.

Recall that the first order conditions in the case of the outward looking representative agent are given by equations (5) and (6) in the text. Differentiate equation (5) with respect to time and divide through by equation (5) using the laws of motion (3) and (4) to get:

$\frac{\dot{U}_{C}}{U_{C}}=-\tilde{A}+\alpha\left(z_{t}-\rho\left[y_{t}-1\right]\right)$

From the utility function specification:

$$
\frac{\dot{U}_{C}}{U_{C}}=-\sigma z_{t}-\gamma \rho(1-\sigma)\left(y_{t}-1\right)
$$


Combining results (A1) and (A2) and solving for $z_{t}=\frac{\dot{c}}{c}$, we get equation (7). Setting $\alpha=0$ attains the COW result, setting additionally $\gamma=0$ yields the result for the case of no habits.

To obtain the stable arm equation, observe that in the steady state

$$
z_{s s}=\rho\left(y_{s s}-1\right)
$$

To derive the steady state solutions for the ratio of consumption to habits and the consumption growth rate, set (A3) equal to (7) and solve for consumption to habits ratio, shown in (9). Then substitute (9) into (A3) to obtain the steady state solution for consumption growth rate, shown in (8). Properties of (8) shown in the phase diagram in Figure 1 follow from the assumption: $y>1$

Next, we want to derive equation (10), the steady state ratio of broad capital to habits. To do so, first differentiate the ratio of capital to habits with respect to time, then use (3) divided through by $x$ and (4) divided through by $h$ to substitute for the growth rates of capital and habits respectively.

$$
\left(\frac{x}{h}\right) \equiv \frac{x}{h}\left[\frac{\dot{x}}{x}-\frac{\dot{h}}{h}\right]=0
$$

In steady state, ratio of capital to habits does not grow, so that $\left(\frac{\dot{x}}{h}\right)_{S S} \equiv 0$. Using this in (A4) and solving for $x / h$ ratio, we obtain equation (8) in the text. 